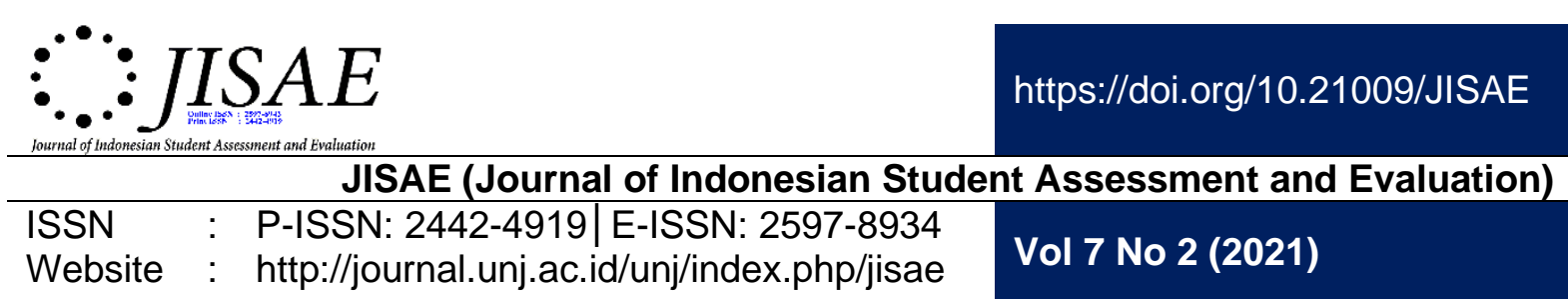

\title{
EMERGING ISSUES IN EDUCATIONAL MEASUREMENT: AUTHENTIC ASSESSMENT
}

\author{
Abubakar Ukashatu' \\ Kano State Polytechnic \\ Kano-Nigeria
}

\author{
Muhammad Muhammad Suleiman² \\ Kano State Polytechnic \\ Kano-Nigeria
}

\section{MusbahuAbdulkahar Mahmoud ${ }^{3}$ \\ Bayero University, Kano \\ Kano-Nigeria}

\begin{abstract}
Authentic assessment is a tool of evaluating students learning applicable to real world situation. It is unavoidable tools for modern assessment of learning outcomes. It can be apply as formative or summative assessments or for both assessment types. This paper attempted to examined the concept of assessment and its types, the concept of authentic assessment and its categories, the forms of authentic assessment, the tools used for authentic assessment, methods used in authentic assessment, steps involved in authentic assessment, advantages of authentic assessment, challenges of authentic assessment among others. The paper concludes that it is a high time for authentic assessment to replace traditional methods of assessment in all level of learning. The paper also recommended that the Curriculum Planners should design a curriculum based on types of authentic assessment for all levels of learning, the application of authentic assessment at all levels of learning, time has comes to move from traditional method of assessment to authentic assessment form and required competencies must be possessed by the teacher in order to carry out authentic assessments through proper training.
\end{abstract}

Keywords: Authentic, Assessment, Real World,

\section{Keywords: Authentic, Assess
Rubrics, Portfolios.}

Address for Correspondence:

abukashat@gmail.com

2muhdkd@gmail.com

3 musbahuabdulkaharmahmud@yahoo.com

\section{INTRODUCTION}

Assessment is an integral part of the learning process as it frames what students learn and achieve (Boud, 2010). One of the principal roles of a teacher in the education enterprises is to effectively instruct learners in order to bring about desirable changes in the behaviours; a way of ascertaining these behaviors is through assessment process (Brown and Race, 2013). Not all of what teachers' teach can be assessed by paper and pencil tests or by multiple choice items question. Students need to demonstrate what they learned applicable to real world situation. Authentic assessment serves as an alternative to conventional assessment which is limited to paper-and-pencil test that emphasize objective measurement. 
The purpose of authentic assessment is to provide students with ample opportunities to engage in authentic tasks so as to develop, use, and extend their knowledge and other $21^{\text {st }}$ century competencies (Nitko, 2004). Internationally recognized assessment expert Wiggins G. (1993) extols the value in utilizing authentic assessments instead of standardized tests.

Many teachers believe that there is a more effective assessment strategy, these teachers use testing strategies that do not focus entirely on recalling facts, instead, they ask students to demonstrate skills, knowledge and concepts they have learned. Students need to demonstrate what they learned that is performance based (based on constructivist learning theory).

Albeit Eistein stated that not everything that counts can be counted and not everything that can be counted, counts. That sentiment captures the philosophy behind the many types of authentic assessment also known as performance, alternative or direct assessments.

Therefore, the objective of this paper is to discuss the concept of authentic assessment with all its ramifications.

\section{Concept of Assessment - Traditional}

Assessment defined by Anunobi (1998), as a process in which one make a judgement about a person or situation. Assessment data effects student advancement, placement, and grades, as well as decisions about instructional strategies and curriculum.

Dietel, Herman, and Knuth (1991) defined Assessment as "any method used to better understand the current knowledge that a student possesses." This implies that assessment can be as simple as a teacher's subjective judgement based on a single observation of student performance, or as complex as a five-hour standardized test. Through assessment, decisions about grades, advancement, placement, instructional needs, and curriculum are affected. For any teaching and learning to be meaningful, assessment of students learning must be effective. In this study, assessment has to do with the collecting data in order to pass judgement on the application of ICT in teaching and learning.

Assessment is a series of activities to obtain, analyze, and interpret data about the process and learning outcomes of students conducted systematically and continuously, so that it becomes meaningful information in decision making. Assessment is very important, because assessment can be used in providing important information, including determining the learning outcomes of students, measuring the extent to which the success of the teacher in carrying out learning during the teaching and learning process, and measuring the extent of students' ability to follow and understand the subject matter that has been taught.

Arifin (2013) assessment is a systematic and continuous process or activity to gather information about the process and results of student learning in order to make decisions based on certain criteria and considerations.

\section{Concepts of Assessment - Authentic}

According to Wiggins (1989), authentic assessment is a "true test" of intellectual achievement or ability because it requires students to demonstrate their deep understanding, high-order thinking, and complex problem solving through the performance of exemplary tasks. Authentic assessments replicate real-world challenges and "standard of performance" that experts or professionals typically face in the field. Wiggins (1990) gives a basic definition of authentic assessment by saying, "Assessment is authentic when we directly examine student performance on worthy Intellectual tasks". 
Stinggins (1987) define Authentic Assessment as a performance assessments call upon the examinee to demonstrate specific skills and competencies, that is, to apply the skills and knowledge they have mastered.

Authentic assessment is "a form of assessment in which students are asked to perform real world tasks that demonstrate meaningful application of essential knowledge and skills" (Mueller, 2011).

O'Malley, (2011), defines Authentic Assessment as a form of assessment in which students are asked to perform real-world tasks that demonstrate meaningful application of essential knowledge and skills.

Sa'ud (2013) explains that authentic assessment is a process carried out by the teacher to gather information about the development of student learning. The gathering of this information was made by using students' portfolio. Authentic Assessment aims to evaluate students' abilities in 'real-world' contexts. In other words, students learn how to apply their skills to authentic task and projects. An authentic assessment usually includes a task for students to perform and a rubric by which their performance on the task will be evaluated. For example, authentic assessments ask students to read real texts, to write for authentic purposes about meaningful topics, and to participate in authentic literacy tasks such as discussing books, keeping journals, writing letters, and revising a piece of writing. Both the material and the assessment tasks look as natural as possible.

Therefore, authentic assessment is a process of collecting, reporting and using information about student learning outcomes in participating and being responsible for learning. Competencies must be possessed by the teacher in order to carry out authentic assessments include: carefully reviewing Competency and Basic Competency Standards, planning authentic assessments with appropriate assessment techniques, applying various types of assessment techniques appropriately, evaluating learning outcomes aspects of knowledge, attitudes and proportional skills, and processing the assessment data appropriately in accordance with the Assessment Guide, and writing the competency achievement of students on report cards in a qualitative descriptive form that is easily understood by relevant parties including parents or guardians of students. It is also a process of collecting, reporting and using information about student learning outcomes in participating and being responsible for learning in real world situation.

Mueller (2011) stated that authentic assessment is also known by other names; performance-based assessment, direct assessment and alternative assessment.

a) Performance Assessment (or Performance-based). So called because students are asked to perform meaningful tasks. For these educators, authentic assessments are performance assessments using real-world or authentic tasks or contexts.

b) Alternative Assessment. So called because Authentic Assessment is an alternative to traditional assessments.

c) Direct Assessment. So called because Authentic Assessment provides more direct evidence of meaningful application of concepts, knowledge and skills.

Thus, in Authentic Assessment, assessment drives the curriculum. That is, teachers first determine the tasks that students will perform to demonstrate their mastery, and then a curriculum is developed that will enable students to perform those tasks well, which would include the acquisition of essential knowledge and skills. This has been referred to as 'planning backwards' (McDonald, 1992). 


\section{Brief History of Authentic Assessment}

The term "authentic assessment" wasfirst coined in 1989, by Grant Wiggins. According to Wiggins (1989), authentic assessment is a "true test "of intellectual achievement or ability because it requires students to demonstrate their deep understanding......

However, some authors argued that authentic assessment was first introduced by Arch Bald and Newman, (1988), they associate "authentic" with achievement i.e. authentic achievement.

\section{Theories that backed Authentic Assessment}

The John Dewey's theory of pragmatisms emphases the need to learn by doing. Dewey approach was true child-centeredapproach, he criticize the traditional approach to teaching where teacher stand in front of a group of student who are all sitting in rows and deliver information and the job of the student is usually to receive and reproduce it in some form of a written test. To Dewey, the role of the teacher is to be more of facilitator than an instructor. Dewey inspired the use of project method in his laboratory school at the University of Chicago from 1896 to 1904 . Children were expected to learn context that was relevant to their real world life.

Another theory was constructivism theory advocated by Jean Piaget, (1971). Constructivism suggests that learners construct knowledge out of their experience. It promotes active learning or learning by doing .Constructivism emphasizes experimentation, research projects, field trip, and class discussions.

Steps Involved in Authentic Assessment

a) Identification of desired learning out comes.

b) Student communication and consultation.

c) The development of rubrics and marking criteria.

d) Assessment implementation, scoring and interpretation of result.

e) Evaluation and reflection. (Fook and Sidhu, 2010)

\section{Types of Authentic Assessment}

Sani (2016) states that authentic assessment is an assessment that directs students to demonstrate the skills and competencies needed to overcome problems and situations encountered in the real world. Meanwhile, Nurgiyantoro (2008) states that authentic assessment is an assessment of tasks that resemble reading and writing activities as well as in the real world and in school. The aim is to measure various skills in various contexts that reflect the situation in the real world where these skills are used. Arifin, (2013) states that the types of authentic assessments include

1) Performance Assessment

2) Project Assessment

3) Portfolio Assessment

4) Written Assessment

\section{METHODS}

According to O'Malley and Pierce, (2011), identified seven (7) methods/types of authentic assessment below:

a) Oral Interview: Here the teacher asks students question about personal background, activities, reading and interest. It is conducted over successive days with each student and record observations on interview guide.

b) Story or Test retelling: Student retells main ideas or selected details of text experienced through listening or reading. It is scored with rubric or rating scale. Ithelps to determine reading comprehension, reading strategies and language development. 
c) Writing Sample: Here student generate narrative, expository, persuasive or reference paper. Student produce written document, it is used to determine writing process. It is also scored with rubric or rating scale.

d) Projects/Exhibitions: Student complete experiment in content areas, working individually or in group. Student makes formal presentation, written report or both. It is scored with rubric or rating scale.

e) Constructed Response Item: Here students respond in writing to open-ended questions. Student produce written report, it is usually scored with rubrics or rating scale.

f) Teacher Observation: Teacher observes student attention, response to instructional materials or interaction with other students. It is used in class room setting, take little time and scored with rating scale.

g) Portfolio: Focused collection of collection of student work to show progress overtime. It integrates information from a number of sources, gives overall picture of the student performance and learning, and calls for student self- assessment.

\section{Authentic Assessment Tools}

\section{RESULT}

Karge, (1998) and Morris (2001), describe a variety of authentic assessment tools that are used to increase students' engagement and make learning more relevant. These include: Role play and drama, students' portfolio, rubrics, utilizing multiple information sources, group work e.t.c.

Terminologies used in Authentic Assessment

Students Portfolio: A student portfolio is a collection of student work and related material that depicts a student's activities, accomplishment, and achievement (Scherba, 2002). Portfolio is a container of evidence of student skills and learning, but also a picture of their development through the school year. There are two types of portfolio i.e. process portfolio, product portfolio.

a) Process portfolio. It documents the stages of learning and provide a progressive record of student growth.

b) Product portfolio. It demonstrates mastery of a set of learning objectives.

The Rubrics: The rubrics explain what is necessary to be included in the portfolio and how 'completeness' is determine for each required item. An item will be marked incomplete if it does not include all necessary components according to the rubrics.Rubrics provide guideline for assessing the degree to which portfolio items demonstrate that, desired learning outcome were achieve. The development and provision of rubrics have been found to lower student anxiety, increase student confidence and aid a sense of objectivity.

\section{Uses /Application of Authentic Assessment}

Research whole heartedly supports the use of authentic assessment in classroom environment. Food and Sidhu. (2010), examine the implementation of authentic assessment in high education through qualitative methodology including interviews, document analysis, and class room observations. In fact, authentic assessment is applicable in all spares of life e.g. class room, biological laboratory, music jury, acting in a play, etc.

Authentic assessment presently can be uses/apply mainly in the assessment of students of building related courses, earth and environment courses, law courses, vocational and technical education courses, technical and vocational education and training courses, computing and information technology, engineering. 
The fact is that the application of authentic assessments is very difficult to understand. Whereas the skills assessment guide issued by the Ministry of Education and Culture in 2013 states that the assessment of student skills can be done through portfolio assessment, performance assessment or project appraisal, the determination of assessment techniques is based on the competency characteristics of the skills to be measured.

The fact is that the application of authentic assessments, especially in elementary schools, according to the teacher, the assessment of skills is very difficult to understand. Whereas the skills assessment guide issued by the Ministry of Education and Culture in 2013 states that the assessment of student skills can be done through portfolio assessment, performance assessment or project appraisal, the determination of assessment techniques is based on the competency characteristics of the skills to be measured.

\section{Advantages of Authentic Assessment}

Authentic assessment has played a pivotal role in driving curricular and instructional changes in the context of global educational reforms. Scholars have identified numerous advantages of authentic assessment, some of them are:

a) Authentic assessment encourages the social aspects of learning by enabling active participation and deeper learning.

b) It lead student to move from being consumers of knowledge to creators of knowledge.

c) Authentic assessment facilitates greater level of self-reflection among students. Give teachers more flexibility in instructions.

d) Research has shown that following authentic assessment, students are more selfregulating and autonomous learners.

e) Authentic assessment allowed assessment that meets the need of the learners by giving authenticity and usefulness to result.

f) Team work.

g) It also allowed student with real-world experience, while protecting them from harmful or irrelevant elements.

h) It promotes creativity.

\section{Challenges of Authentic Assessment}

Despite its many benefits, a number of challenges have been identified. Ewing, (1998) sounds a note of caution about application of authentic assessment. Some of the challenges are:

a) Student may initially be resistant to authentic assessment due to uncertainty about what is required and how it will be marked.

b) Some student may find authentic assessments challenging due to the increase emphasis on language and group work which is frequently entails.

c) Students may also perceive that their varying abilities and levels of real world experience might impact upon their marks.

d) Another challenge that may be experience by both students and teachers is that of cost and time, authentic assessment requires a greater investment of time.

e) Authentic assessment may not be appropriate in all levels.

f) Expectation may be too high.

g) Usually, authentic assessments take longer to plan, complete, and evaluate then other methods of assessment.

h) It is difficult to ensure assessment accurately aligns with curriculum and standard. Because under authentic assessment, assessment drive curriculum, not curriculum driving assessment. 
i) Subjective nature of grading may lead to bias.

j) Authentic assessment may not be practicable for large enrollment courses.

\section{CONCLUSIONS}

To secure a fair and complete picture of students' performance, teachers should use a variety of strategies over a period of time and in difference situation. All aspects of educationists, curriculum planners, test experts, psychometrics, researchers, technologists, scientists, cousellors, psychologists, educational administrators and so on should come to an aid to assessment methods in this modern era of information technology. But Ewing (1998) argue that authentic assessment will not replace traditional assessment methods, but that there is future for such methods.

\section{Recommendations}

However, below are some of the recommendations with regard to authentic assessment:

a) Curriculum planners should take into cognizance how world is changing, they should design a curriculum that help the students and society and design a curriculum based on types of authentic assessment.

b) We recommend the application of authentic assessment at all level of learning.

c) Time has come for us to move from traditional method of assessment to authentic assessment.

d) Competencies must be possessed by the teacher in order to carry out authentic assessments include: carefully reviewing Competency and Basic Competency Standards, planning authentic assessments with appropriate assessment techniques, applying various types of assessment techniques appropriately, evaluating learning outcomes aspects of knowledge, attitudes and proportional skills, and processing the assessment data appropriately in accordance with the Assessment Guide in elementary school, and writing the competency achievement of students on report cards in a qualitative descriptive form that is easily understood by relevant parties including parents or guardians of students.

e) It is essential that any teacher who want to introduce method of authentic assessment has a clear plan of what they want achieved.

f) It is needed to develop authentic assessment instruments that could help teachers to conduct assessments, especially on skills aspects, the researchers used Research and Development ( $R$ \& D) methods.

g) The product is developed in the form of an instrument guide for authentic assessment of aspects participation skills in grade IV elementary school.

\section{REFERENCES}

Alfabeta ----------. (2016). Qualitative Quantitative Research Methods and R \& D. Bandung: AlfabetaSumaryadi, I Nyoman. (2005). Effectiveness of Implementation of Regional Autonomy Policy. Jakarta: Main Image Suryosubroto. (2002). The Process of Teaching and Learning in Schools. Jakarta: RinekaCipta

Arifin, Z. (2013). Learning Evaluation. Bandung: PT. Teenager Rosdakarya. Ministry of Education and Culture Directorate General of Basic Education (2013). Technical Guidance for Assessment in Primary Schools. Jakarta: Ministry of Education and Culture.

Boud, D. (2010). Assessment2020: SevenPropositions for Assessment Reform in High Education. Sydney: Australian Learning and Teaching Council.

Brown, S. \& Race, P. (2013). Using Effective Assessment to Promote Learning. IL. 
Bumi Aksara (2014). Scientific Learning for the Implementation of the 2013 Curriculum. Jakarta: Earth Literacy A copy of the Annex to the Republic of Indonesia Minister of Education and Culture Regulation Number 66 of 2013 concerning Educational Assessment Standards Sugiyono. (2009). Educational Research Methods ApproachQuantitative, Qualitative, and R \& D. Bandung:

De Casto-Ambrosetti, D. and Cho, G. (2005). Synergism in Learning: A Critical Reflection of Authentic Assessment. The High School Journal, 89 (1), pp. 5762.

Dewey, J. (1938). Experience and Education. New York; Collier. Experience Based Learning. (2005). Corporate Team Building. Retrieved April 18,2011, from http;//www.ebl.org.

Ewing, S.C. (1998). Alternative Assessment: Popularity, Pitfalls and Potential. [Electronic Version] Assessment Update 10, 1-2, 11-12.

Fook, C. Y. and Sidhu, G. K. (2010). Authentic Assessment and Pedagogical Strategies in High Education. Journal of Social Science 6(2), 153-161.

Karge, B. D. (1998). Knowing What to Teach: Using Authentic Assessment to Improve Classroom Instruction. Reading and Writing Quarterly. 14(3), 319-331.

Mueller, T. (2011). Authentic Assessment Toolbox. North Central College, Naperville, IL. Available at: http;//jfmueller.faculty.noctrl.edu/toolbox/

Nitko, A. J. (2014). Educational Assessment of Students ( $4^{\text {th }}$ ed). Upper Saddle River, N. J: Pearson / Merrill Pretice Hall.

Nurgiyantoro, Buchan. (2008). Authentic Assessment in Language Learning. Cakrawala Journal No.3. Yogyakarta: Gajah Mada University Press. Government Regulation No.32 of 2013 concerning National Assessment Standards. Minister of Education and Culture. No.104 of 2014. Guidelines for Assessment of Learning Outcomes by Educators in Basic Education \& Education.

O'Malley, M.J. and Pierce, L.V. (2011). Form Authentic Assessment for English Language Learners. Retrieved From www.doe.in.gov/english language learning.

Sani, R. A. (2016). Authentic Assessment. Jakarta: Wiggins, G. (1989). A true Test: Toward More Authentic and Equitable Assessment. Phi Delta, Kppan. 